Article

\title{
An Experimental Study on Effects of Corrosion and Stirrups Spacing on Bond Behavior of Reinforced Concrete
}

\author{
Konstantinos Koulouris * (D) and Charis Apostolopoulos \\ Department of Mechanical Engineering and Aeronautics, University of Patras, 26500 Patras, Greece; \\ charrisa@upatras.gr \\ * Correspondence: kkoulouris@upnet.gr; Tel.: +30-2610996377
}

Received: 24 August 2020; Accepted: 30 September 2020; Published: 4 October 2020

check for updates

\begin{abstract}
The current experimental study consists of part of an extensive and ongoing research on bond behavior of RC elements damaged by corrosion, focusing on stirrups spacing effect on bonding. For this, RC specimens with different cases of stirrups spacing were casted. Accelerated corrosion was induced in order to simulate the slow process of nature corrosion on RC specimens and the corrosion damage was estimated in terms of mass loss of steel bars and average width of surface concrete cracking. Subsequently, pull-out tests were carried out to examine the bonding resistance between steel and concrete. The study indicates the great influence of density of stirrups on the percentage mass loss of the embedded reinforcing bar, accompanied by width of surface concrete cracking, as well as on bond strength between steel and concrete. The results of bond stress-slip curves show that the densification of stirrups plays a significant role in bonding, leading to higher bond strength values and delaying the degradation of bond loss as corrosion damage increases. However, it becomes apparent that, although the densification of stirrups $(\Phi 8 / 60 \mathrm{~mm})$ result in the full anchorage of steel-reinforcing bars, it may be inappropriate, since it can lead to a substantial increase in costs and a rapid rise in corrosion rate, due to potential increase. Furthermore, the recorded values of relative slip at bond strength are between 1 and $3 \mathrm{~mm}$, regardless of corrosion damage or concrete cracking, which depends on the ribs geometry and crushing of concrete in front of them. To conclude, the results of the present manuscript indicate that the increase in transverse reinforcement (stirrups) percentage plays a key role in the durability of reinforced concrete elements and in bond strength maintenance between rebar and concrete.
\end{abstract}

Keywords: steel corrosion; concrete surface cracking; stirrups; bond strength; bond loss; slip; pull-out tests

\section{Introduction}

In Reinforced Concrete (RC) elements, the bond mechanism between steel bars and the surrounding concrete plays the key role, in order to ensure that steel reinforcement and concrete react as one material and the tensile forces are safely transferred from steel to concrete. Due to its high bearing capacity and ductility, compared to the low production costs, reinforced concrete is one of the most widely used construction materials in the existing building stock.

However, the corrosion of steel reinforcement consists of the main durability problem of RC structures, affecting not only their appearance but also their mechanical performance and structural integrity. Recent reports have indicated huge economic impacts due to corrosion damage, since a significant part of the annual budget in many countries is spent on the maintenance, repair, and rehabilitation of RC structures [1,2]. For instance, the results of a study conducted by NACE [1] 
reveal that the cost of corrosion is globally estimated to be USD 2.5 trillion, approximately 3.4 percent of the global GDP.

The corrosion of steel reinforcement is an electrochemical phenomenon, in which steel tends to return to its original form (ore) by forming iron oxides on its surface (rust). In a natural environment, the corrosion process is slow, since the embedded steel bars are initially protected by the concrete cover, which acts as a physical barrier, and by the thin oxide passive layer, which is formed by the high alkalinity of concrete environment $(\mathrm{pH} \approx 12.5)$. However, aggressive environmental factors, such as chloride ions, are penetrated and diffused in concrete through its pores, destroying the abovementioned protection mechanisms (initiation stage of corrosion). When the chloride concentration reaches a critical value, it is considered that the passive layers of the reinforcement are demolished, and then the electrochemical process of corrosion initiates (corrosion onset) [3,4]. The forming oxides on steel surface (rust) occupy a 2 to 6 times greater volume of the attacking mass [5], causing tensile stresses in surrounding concrete and, thereafter, leading to gradual concrete cracking development and spalling of the cover concrete [6], as shown in Figure 1. As a result, the bond mechanism between steel and concrete is significantly affected, and therefore the bearing capacity of RC elements is degraded [7-9].

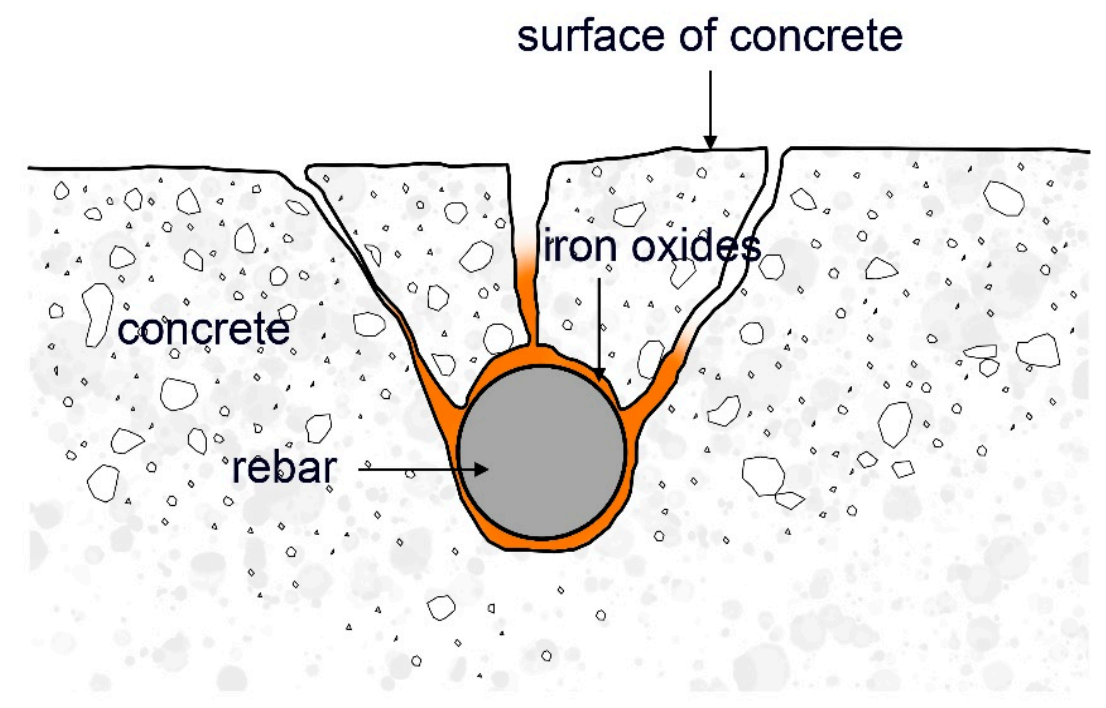

Figure 1. Cracking development and spalling of concrete cover due to oxides of steel reinforcement.

Since steel reinforcement is embedded in concrete and its corrosion damage is difficult to map and quantify, several studies have been conducted with the aim of linking the width of surface cracks with the penetration of the corrosion (or in terms of mass loss) of steel bars; thus, predictive models have been suggested [10-17]. This approach consists of a non-destructive method of corrosion assessment, since crack opening is a useful and representative index of steel bars' damage. The extensive experimental research of Bossio et al. on corroded RC specimens introduced a non-linear model, in which a uniform type of corrosion was assumed, and the limit value of crack width was about $10 \mathrm{~mm}$ [17]. However, the outcomes of various experimental studies differ due to different exposure conditions, cover thicknesses, steel bar geometries, positions of steel bars, etc. Hence, there is a need for further research on this framework in order to define the influencing coefficients and establish specific correlations between the width of surface cracking, the degree of corrosion damage, the cover thickness, the density of stirrups, the concrete class, etc.

Bonding resistance between steel and concrete is mainly determined by chemical adhesion, friction, and the mechanical interlock between steel bar and surrounding concrete [18]. In general, the anchorage of (deformed) reinforcing bars is due to the confinement level. Several studies have indicated the main factors which affect bonding, such as the mechanical properties of concrete, concrete cover, stirrups spacing, relative rib area of deformed steel bars and steel corrosion. Abosrra et al. [19] and Zandi and Coronelli [20] investigated the influence of corrosion on bond behavior, testing specimens 
of different compressive concrete strengths. Apostolopoulos et al. [21], Fischer and Ozbolt [22] and Yalciner et al. [23] carried out accelerated corrosion tests and pull-out to investigate bond loss in the function of different corrosion levels and different concrete cover values. Most experimental studies in the literature have carried out pull-out tests on specimens where the reinforcing bar is set in the center of the cylindrical concrete specimen without transverse reinforcement. Recently, experimental studies by Zandi et al. [24], Lin et al. [25] and Apostolopoulos et al. [21] investigated the impact of both corrosion and stirrups spacing carrying out eccentric pull-out tests on RC elements with the usual design values of concrete cover. However, even today there is a level of uncertainty which depends on the estimation of bond capacity of corroded RC elements. Thus, this experimental study seeks to enhance the current knowledge and provide additional data on the bond behavior of corroded RC elements, taking into account the corrosion damage of the reinforcing bar, as well as the confinement level, through transverse reinforcement (stirrups).

\section{Experimental Procedure}

In this experimental study, the bond behavior of 24 un-corroded and corroded reinforced concrete specimens was investigated. The experimental procedure consists of four main phases: Phase I, the casting and curing of specimens with different amounts of transverse reinforcement; Phase II, the accelerated corrosion of specimens in laboratory for different exposure times in order to achieve different corrosion levels and measure the range of surface cracking on concrete; Phase III, pull-out tests, carried out in order to investigate the bond behavior (bond stress and relative slip between steel and concrete); Phase IV, the breaking of specimens in order to assess the corrosion damage of reinforcement and correlate it with the pull-out results.

\subsection{Materials and Specimens Casting}

It is a fact that in the period 1990-2010, the selected concrete in the majority of structures located in coastal and seismic regions of the Mediterranean (Greece, Italy, Turkey) was class of C20/25, despite the guidelines of EN 206 [26] for the use of higher categories of concrete (e.g., C25/30 or C30/37). Based on the fact that these structures already show symptoms of premature aging, it was considered expedient to develop an extensive, continuous (evolving) experimental study in order to investigate the degradation of bond strength (steel-concrete) in RC structural elements for different levels of artificial corrosion. For this purpose, prismatic reinforced concrete specimens of dimensions $240 \times 200 \times 310\left(\mathrm{~mm}^{3}\right)$ were casted (Figure 2), in which a main reinforcing steel bar, of technical class B500C and nominal diameter equal to $16 \mathrm{~mm}$, was semi-embedded on the top of the specimens with concrete cover c equal to $25 \mathrm{~mm}$. Furthermore, specimens with different amount of transverse reinforcement were tested, in order to investigate the influence of stirrups spacing on the corrosion damage and bond behavior between main steel bar and concrete. Specifically, four cases were tested: (a) specimens without stirrups, (b) specimens with wide stirrups $\Phi 8 / 240 \mathrm{~mm}$, (c) specimens with stirrups $\Phi 8 / 125 \mathrm{~mm}$ and (d) specimens with dense stirrups $\Phi 8 / 60 \mathrm{~mm}$. All stirrups were of nominal diameter equal to $8 \mathrm{~mm}$ and four smooth bars were placed at the corners to stabilize them during the casting procedure.

To permit easy identification of test specimens, special labels of three parts were used; the first part of the label refers to the concrete cover thickness, namely $c=25 \mathrm{~mm}$, then the following part of label represents the amount (density) of stirrups-more specifically, $\mathrm{N}$ refers to the group of test specimens without stirrups, and S240, S120 and S60 refers to the groups of test specimens with stirrups $\Phi 8$ per 240, 120 and $60 \mathrm{~mm}$, respectively. The last digit of each label refers to the corrosion time. Thus, for instance, the 25-S120-4 specimen corresponds to a specimen with cover thickness $25 \mathrm{~mm}$, with wide dense stirrups $\Phi 8$ per $120 \mathrm{~mm}$, and to the fourth (in a row) corrosion time. 

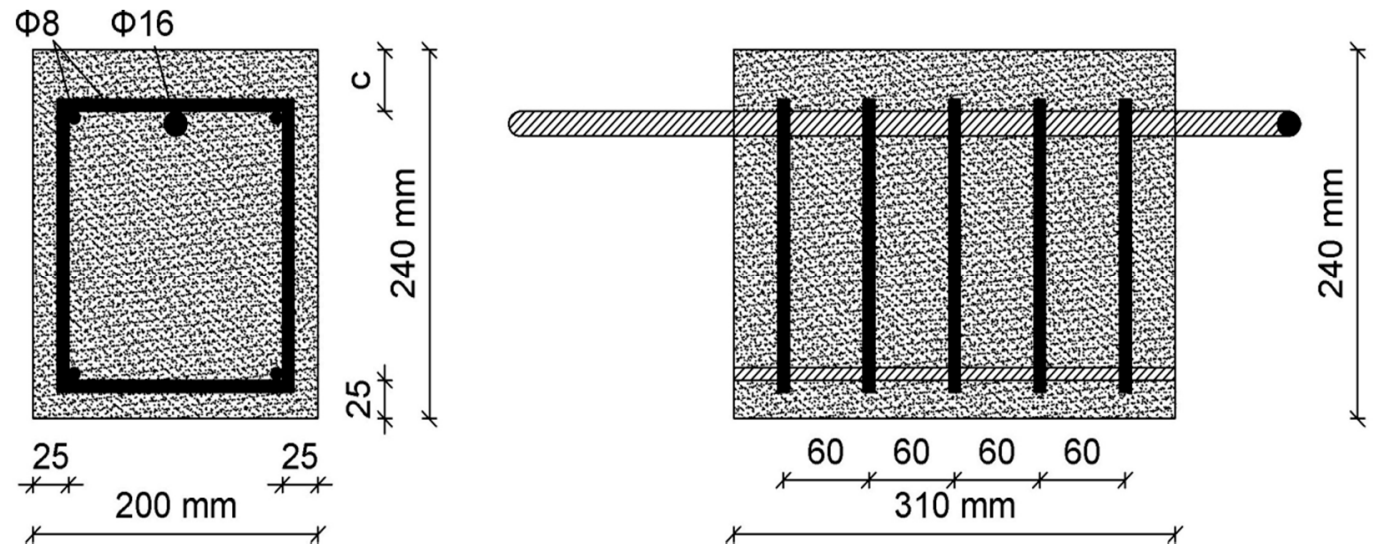

Figure 2. (a) Typical cross-sectional view with cover thickness $=25 \mathrm{~mm}$; (b) longitudinal view (dense stirrups $\Phi 8 / 60 \mathrm{~mm}$ ).

Before mixing the concrete in molds, reinforcing steel bars were carefully cleaned, and their initial mass and total length were documented. With a view to limit the corrosion damage only to the embedded length of main reinforcing bar, and to indicate the influence of corrosion of the main bar on surface concrete cracking and on bond behavior, a 250-mm section of rebar was exposed in corrosion and the rest was protected with a wax layer, and all stirrups were protected with a special anticorrosive coating (epoxy resin). Thereafter, all reinforcement (steel bar and stirrups) were aligned and fastened to the molds to cast the concrete, Figure 3a, compaction of which was conducted with the help of a table vibrator. For the concrete mixture, a Portland cement was used, with water-cement ratio of 0.55 and $20 \mathrm{~mm}$ maximum size coarse aggregate. After the casting, all specimens were kept for three days in a wet environment, then the molds were carefully removed and the curing of specimens was taken place for 28 days in a specially designed room under a temperature of $22{ }^{\circ} \mathrm{C}$ and continuous wetting, Figure $3 \mathrm{~b}$. In parallel, plain concrete cube specimens of $200 \mathrm{~mm}^{3}$ were casted and the average value of 28-day recorded compressive strength was evaluated $f_{\mathrm{c}}=30 \mathrm{MPa}$.
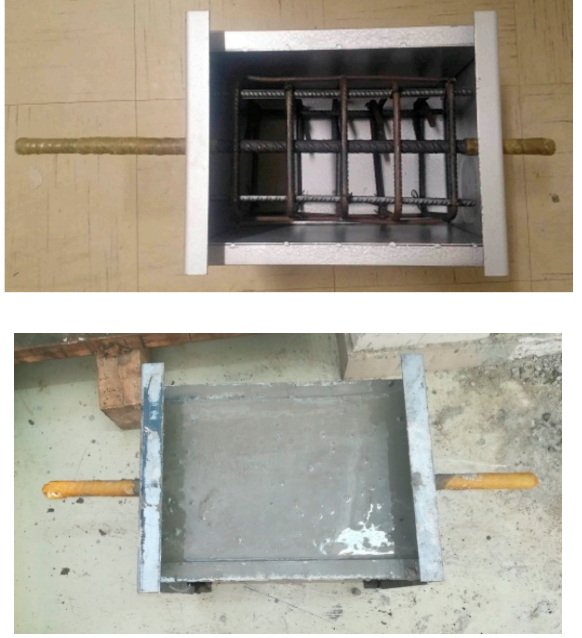

(a)

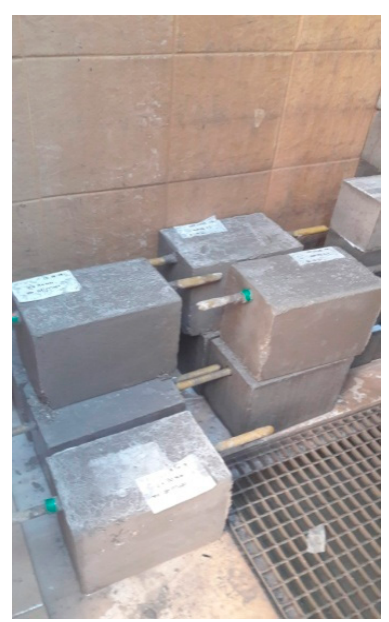

(b)

Figure 3. (a) Installation of steel reinforcement in the molds (up) and concreting of specimens (down). (b) Curing of concrete specimens in a specially designed humidity room. 


\subsection{Accelerated Corrosion Technique}

Due to concrete cover and initial high alkaline level of concrete, the corrosion process in natural environment is slow and takes place over a period of years, even in coastal regions, as there is a period of penetration of the aggressive factors in concrete and the subsequent beginning of corrosion must be passed. In order to accelerate the consequences of steel reinforcement corrosion, laboratory experiments on reinforced concrete specimens were carried out by the anodic corrosion method. This method is simple and widely used, since it has the advantage of fixing different levels of the induced current density on specimens and significantly accelerating the corrosion rate of natural procedure.

Based on the abovementioned technique, a power supply was used to induce corrosion by applying a direct electric current to the semi-embedded reinforcing steel bar, which acted as an anode. Each specimen was placed in a tank, semi-filled with $5 \%$ sodium chloride $(\mathrm{NaCl})$ solution by the weight of water, in the presence of a stainless-steel bar, which acted as cathode of the circuit, Figure 4a. Initially, before the commencement of corrosion experiments, all specimens were moistened continuously for three days in order to full the pores of concrete with the $\mathrm{NaCl}$ electrolyte, and, thereafter, the current was induced to the main reinforcing bar.

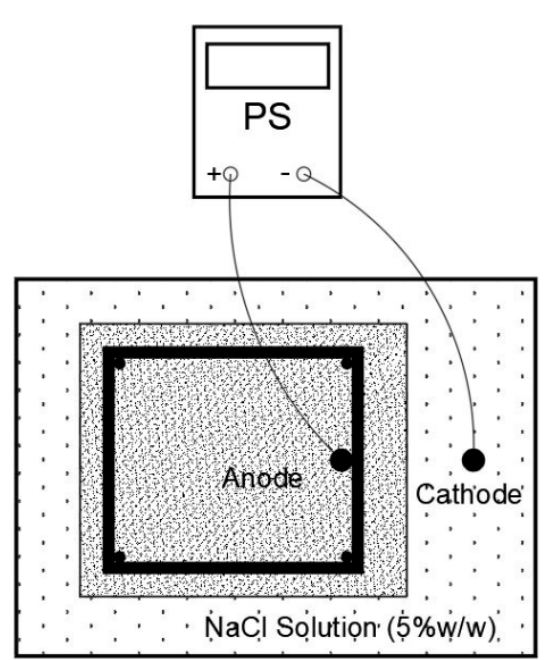

(a)
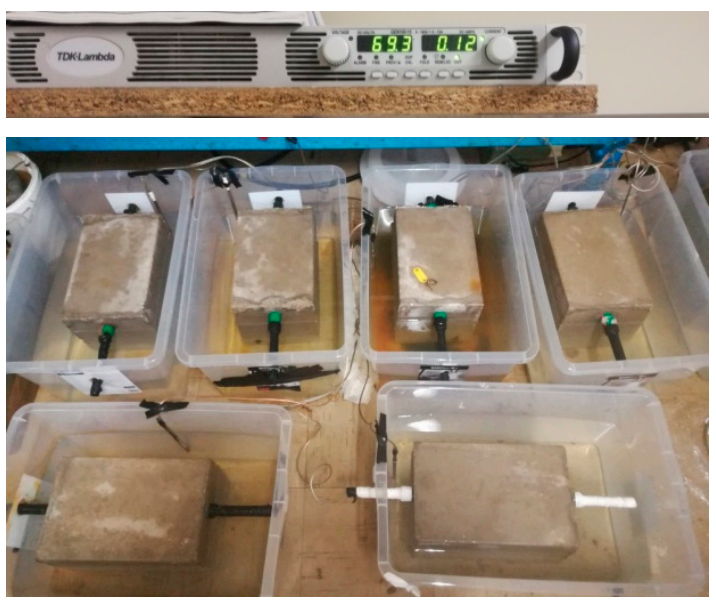

(b)

Figure 4. (a) Simplified procedure of accelerated electro-corrosion. (b) Accelerated corrosion experiments on reinforced concrete (RC) specimens via inducing current.

Solution $5 \% \mathrm{NaCl}$ was selected because it simulates a severe corrosive environment or a coastal environment $[27,28]$ and comes in agreement with existing regulations concerning corrosion tests, such as the B117 ASTM Standard [29]. Additionally, the content of the solution in $\mathrm{NaCl}$ accurately represents the case of the Mediterranean countries, where hot climate results in higher salinity of the seawater, in contrast to northern countries, where river estuaries can be met. A typical example is the Arabian basin, where the recorded salinity is even higher. Furthermore, in Mediterranean countries, the salinity of the sea increases during the summer periods, due to the high temperatures [30,31].

With the aim of simulating the corrosion process and achieving different levels of corrosion damage on reinforcing steel bar, the specimens remained in the cells for different exposure times, inducing current of $0.12 \mathrm{~A}$, via the continuous power supply, Figure $4 \mathrm{~b}$. Based on Lin et al. study [32], which indicated the bond strength reduction owing to corrosion of stirrups, and with a view to estimate the bond loss, only due to the damage to the main reinforcing bar, all stirrups were protected with a special anticorrosive coating (epoxy resin), in order to sufficiently maintain their corrosion resistance, so that the results of pull-out test refer only to the degradation of longitudinal reinforcing bar and are 
not additionally affected by stirrups' corrosion. However, as a result, a significant part of the applied current is consumed at the same time to damage the additional protective material. Thus, the current density value of specimens with different cases of stirrups was not the same, resulting in different experimental times being required to cause a similar level of corrosion damage.

Furthermore, in order to investigate the influence of the reinforcing bar's corrosion on bond behavior, the embedded length of $250 \mathrm{~mm}$ was free to be corroded and the rest of the steel bar was protected by a wax layer.

\subsection{Mapping of Surface Concrete Cracks}

Surface cracking appeared on the concrete of specimens due to the corrosion of steel reinforcement, mainly on the upper side where the main reinforcing bar was placed, as shown in Figure 5a. The average width of these cracks was mapped, measured and calculated in order to estimate the corrosion damage through concrete cracking and to correlate this cracking with bond strength.

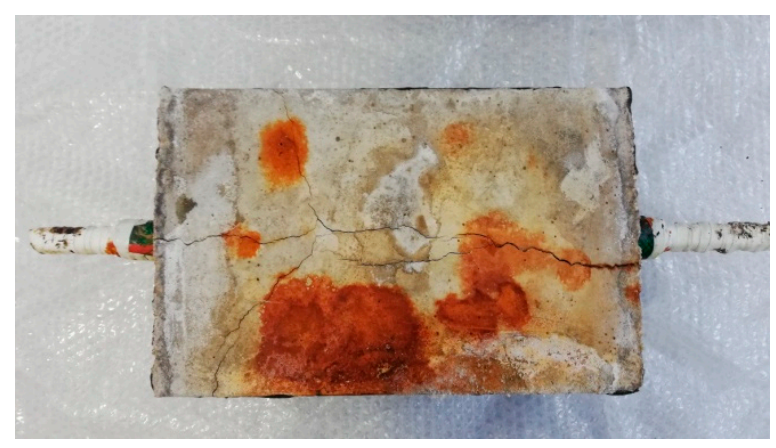

(a)

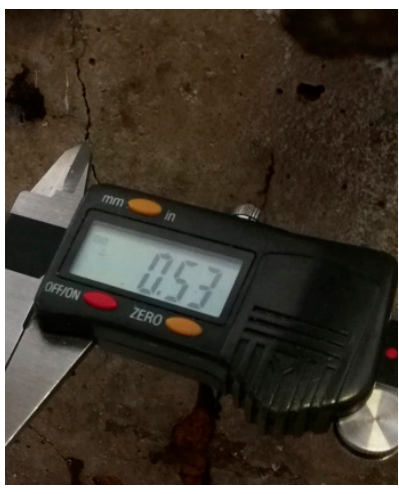

(b)

Figure 5. (a) Surface concrete cracking due to steel corrosion. (b) Measuring of crack width on concrete.

Surface cracks in a clear direction parallel to the longitudinal reinforcing bars were measured along per $5 \mathrm{~mm}$ in distinct segments of 20 to $50 \mathrm{~mm}$ in length, namely, crack width measurements were taken per $5 \mathrm{~mm}$ for each individual crack length using a digital caliper. By way of illustration, an individual measuring of crack width on concrete surface is presented in Figure 5b. From these discrete measurements, the average crack width in each reinforced concrete specimen for each corrosion level was finally calculated.

\subsection{Pull-Out Tests}

Based on ASTM C234-91a [33], pull-out tests were carried out after corrosion experiments and mapping of surface cracks. This method is a simple means of bond mechanism testing on the interface between the steel reinforcement and surrounding concrete.

For this purpose, an apparatus was designed, Figure 6a, which allows the direct transfer of the applied force from the steel bar to concrete. The mechanical tests were performed on a general-purpose servomotor MTS (load capacity of $F_{\max }=250 \mathrm{kN}$ ), where its own fitting and the tested reinforced concrete sample were properly fitted, Figure $6 \mathrm{~b}$.

An external Linear Variable Differential Transformer (LVDT) was set to the free loaded end of reinforcing bar, to monitor the relative slip between the bar and concrete. All specimens were loaded under displacement-control at a constant displacement rate of $0.4 \mathrm{~mm} / \mathrm{min}$. During the mechanical tests, pull-out force and relative slip between steel bar and concrete were automatically recorded using a data logger. 


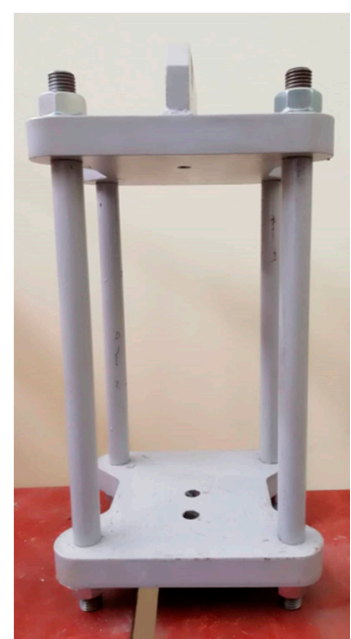

(a)

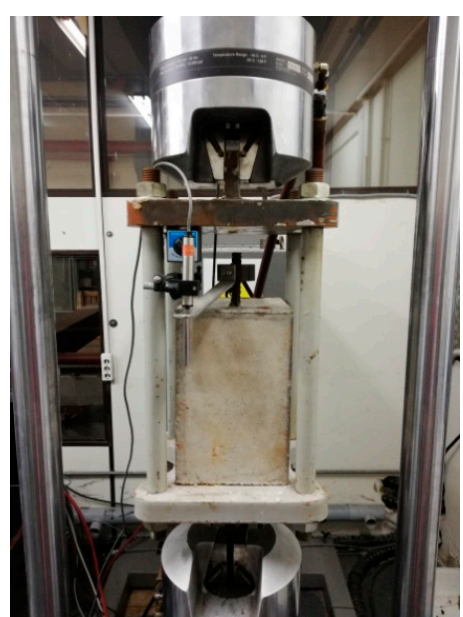

(b)

Figure 6. (a) Apparatus designed for pull-out testing, in order to transfer the force from reinforcing bar to concrete. (b) Experimental pull-out test on semi-embedded steel reinforcing bar.

In order to quantify the bonding resistance between steel and concrete, average bond strength was estimated, taking the nominal diameter of the reinforcement bar into account and considering the bonding stresses as constant and uniform along the embedded length. This simplification leads to lower values than the actually developing ones, especially as the embedded length increases. Thus, the average bond strength between steel and concrete $f_{c b}$ for the embedded length was expressed by Equation (1), as shown in Figure 7

$$
f_{c b}=\frac{F_{\max }}{\pi \cdot D \cdot L_{e m b}}
$$

where $F_{\max }$ is the maximum pull-out load, $D=16 \mathrm{~mm}$ the nominal diameter of the main reinforcing bar, and $L_{\mathrm{emb}}=250 \mathrm{~mm}$ the embedded length.

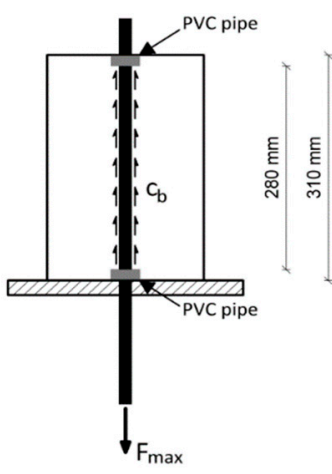

Figure 7. Distribution of bond strength in embedded length—simplification of constant average bond stress.

Furthermore, the maximum pull-out load, $F_{\max }$, the bond loss ratio $f_{\mathrm{cb}, \mathrm{cor}} / f_{\mathrm{cb}, \text { uncor }}$ and the relative slip values corresponding to the maximum pull-out load (bond strength), $s_{\max }$, were recorded.

\section{Results and Discussion}

After concreting and curing period of all specimens, no surface crack on concrete was noticed. Hence, all recorded surface crack widths were deemed due to the corrosion of steel reinforcement. The results of the current experimental work are summarized in Table 1 for each corrosion time. 
In particular, the assessment of corrosion damage is depicted through percentage mass loss of the main steel bar, by measuring of weight after pull-out tests, and through the average surface cracking width of concrete. Moreover, derived from pull-out tests for each corrosion level, the ultimate pull-out load, bond strength, bond loss ratio and relative slip at bond strength are noted. The bond loss ratio $f_{\mathrm{cb}, \mathrm{cor}} / f_{\mathrm{cb} \text {, uncor }}$ refers to proper normalization of the loss of bond strength between corroded reinforcement and concrete, and subsequently the reduction in the load-carrying capacity of the reinforced concrete element.

Table 1. Experimental results obtained from accelerated corrosion tests and pull-out tests (mass loss of steel bar, average width of surface concrete cracking, maximum load $\left(F_{\max }\right)$, bond Strength $\left(f_{\mathrm{cb}}\right)$, bond loss ratio $\left(f_{\mathrm{cb}, \mathrm{cor}} / f_{\mathrm{cb}, \text { uncor }}\right)$ and slip at bond strength $\left(s_{\max }\right)$.

\begin{tabular}{|c|c|c|c|c|c|c|}
\hline Specimen & $\begin{array}{c}\text { Mass Loss } \\
(\%)\end{array}$ & $\begin{array}{c}\text { Average Crack } \\
\text { Width }(\mathrm{mm})\end{array}$ & $\begin{array}{l}\text { Maximum } \\
\text { Load (kN) }\end{array}$ & $\begin{array}{c}\text { Bond Stress } \\
\text { (MPa) }\end{array}$ & $\begin{array}{l}\text { Bond Loss } \\
\text { Ratio (MPa) }\end{array}$ & $\begin{array}{l}\text { Slip at Bond } \\
\text { Strength (mm) }\end{array}$ \\
\hline $25-\mathrm{N}-0$ & 0 & 0 & 65.1 & 5.18 & 1 & 1.76 \\
\hline $25-\mathrm{N}-1$ & 0.97 & 0.20 & 57.3 & 4.56 & 0.88 & 2.14 \\
\hline $25-\mathrm{N}-2$ & 2.05 & 0.35 & 40.4 & 3.21 & 0.62 & 2.84 \\
\hline $25-\mathrm{N}-3$ & 4.12 & 0.55 & 26.7 & 2.12 & 0.41 & 3.55 \\
\hline $25-\mathrm{N}-4$ & 5.83 & 0.95 & 12.4 & 0.98 & 0.19 & 4.57 \\
\hline $25-\mathrm{N}-5$ & 7.73 & 1.45 & 9.8 & 0.78 & 0.15 & 0.78 \\
\hline 25-S240-0 & 0 & 0 & 88.5 & 7.04 & 1 & 1.44 \\
\hline 25-S240-1 & 1.03 & 0.35 & 68.1 & 5.42 & 0.77 & 1.69 \\
\hline 25-S240-2 & 2.22 & 0.55 & 53.1 & 4.22 & 0.60 & 2.12 \\
\hline $25-S 240-3$ & 4.38 & 0.85 & 45.1 & 3.59 & 0.51 & 1.84 \\
\hline 25-S240-4 & 5.74 & 1.05 & 42.5 & 3.38 & 0.48 & 2.40 \\
\hline $25-S 240-5$ & 8.47 & 1.45 & 35.4 & 2.82 & 0.40 & 1.93 \\
\hline 25-S120-0 & 0 & 0 & 114.4 & 9.10 & 1 & 1.27 \\
\hline 25-S120-1 & 1.17 & 0.35 & 108.6 & 8.65 & 0.95 & 2.07 \\
\hline $25-S 10-2$ & 3.22 & 0.70 & 93.8 & 7.46 & 0.82 & 1.48 \\
\hline 25-S120-3 & 5.84 & 1.20 & 81.2 & 6.46 & 0.71 & 1.29 \\
\hline 25-S120-4 & 7.06 & 1.10 & 57.2 & 4.55 & 0.50 & 1.96 \\
\hline $25-S 120-5$ & 8.32 & 1.40 & 77.8 & 6.19 & 0.68 & 2.05 \\
\hline $25-S 60-0$ & 0 & 0 & 119.8 & 9.53 & 1 & 1.83 \\
\hline $25-S 60-1$ & 0.85 & 0.20 & 131.7 & 10.48 & 1.10 & 1.46 \\
\hline $25-S 60-2$ & 1.72 & 0.55 & 122.2 & 9.72 & 1.02 & 2.37 \\
\hline 25-S60-3 & 2.96 & 0.65 & 110.2 & 8.77 & 0.92 & 2.13 \\
\hline $25-\mathrm{S} 60-4$ & 5.82 & 0.90 & 107.8 & 8.58 & 0.90 & 2.36 \\
\hline $25-S 60-5$ & 8.68 & 1.00 & 98.2 & 7.81 & 0.82 & 3.50 \\
\hline
\end{tabular}

The results of the accelerated corrosion procedure showed that an increase in corrosion time leads to more intense concrete cracking. As previous studies reported, crack width does not obey any specific rule with respect to mass loss of steel reinforcement, as it may, to some extent, depend on the class and porosity of concrete, steel bar geometry, concrete cover and ratio of transverse reinforcement $[17,21]$. In former studies, the non-linear relationship between the crack width on concrete surface and the uniform corrosion penetration has been presented via the corresponding models $[11,12,15,16]$. However, it is well known that corrosion damage on a steel reinforcement embedded in concrete is characterized by strong non-uniformity, which is reflected by pits on the surface of reinforcing bars and local cross-sectional reductions. Figure 8 shows the significant reduction in the cross-section of a 
corroded reinforcing bar, located only in a small length of it, while the rest of its length has a slow corrosion rate. The mass loss index, used to estimate corrosion damage, corresponds to the mass loss of material along its entire tested length, which is exposed to corrosion. Thus, mass loss gives an overview of corrosion damage, without attributing it to local phenomena. Although it can be explained from the above-mentioned that mass loss index is widely followed by the scientific community, it lags behind the concept of cross-sectional loss of reinforcing bars, and it cannot always correlate the corrosion damage of steel reinforcement with the surface cracking of concrete or the bond loss between steel and concrete.

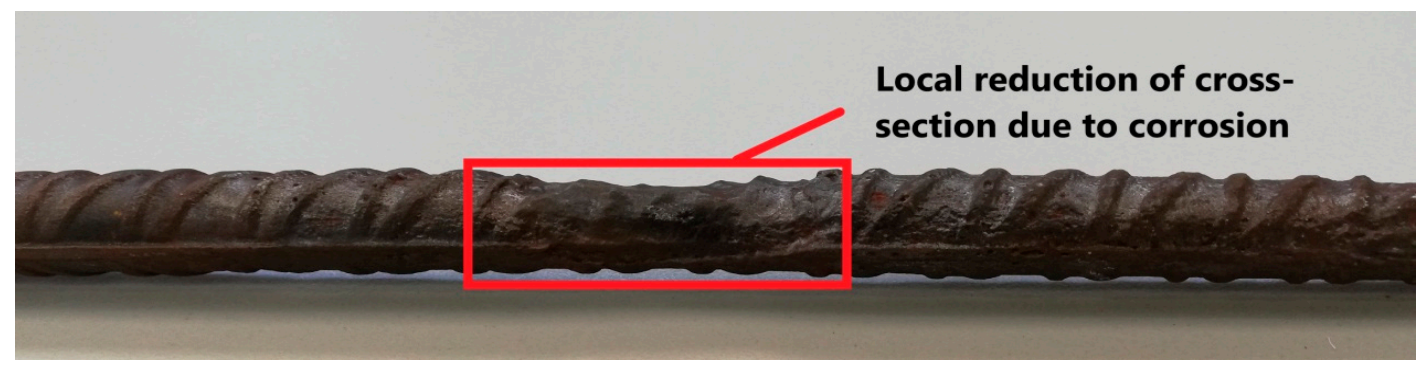

Figure 8. Significant local cross-sectional reduction in reinforcing steel bar due to corrosion.

Nonetheless, surface crack width tends to be an appropriate index for the bond strength evaluation, as there a correlation has been indicated between these two parameters. More specifically, the current research agrees with the experimental results, which have shown that the bond loss of reinforced concrete due to corrosion is in line with the increase in surface cracking. In this framework, predictive models of bond loss have been introduced by different researchers [21,22,25,34-38]. Apostolopoulos and Koulouris [21] proposed exponential predictive curves of bond loss in tandem with surface cracking width, by non-linear regression analysis, based on experimental results (Figure 9), by drawing attention to the influence of stirrups spacing. The functions of predictive models are shown in Equation (7)

$$
\frac{f_{c b}^{c o r}}{f_{c b}^{u n c o r}}=e^{-A \cdot c_{w}}
$$

where $A$ is a parameter that depends on the concrete cover thickness (c) and the amount of transverse reinforcement (stirrups spacing or absence of stirrups). The values of parameter $A$ for each predictive model, and the corresponding values of the $\mathrm{R}^{2}$ coefficient, are presented in Table 2.

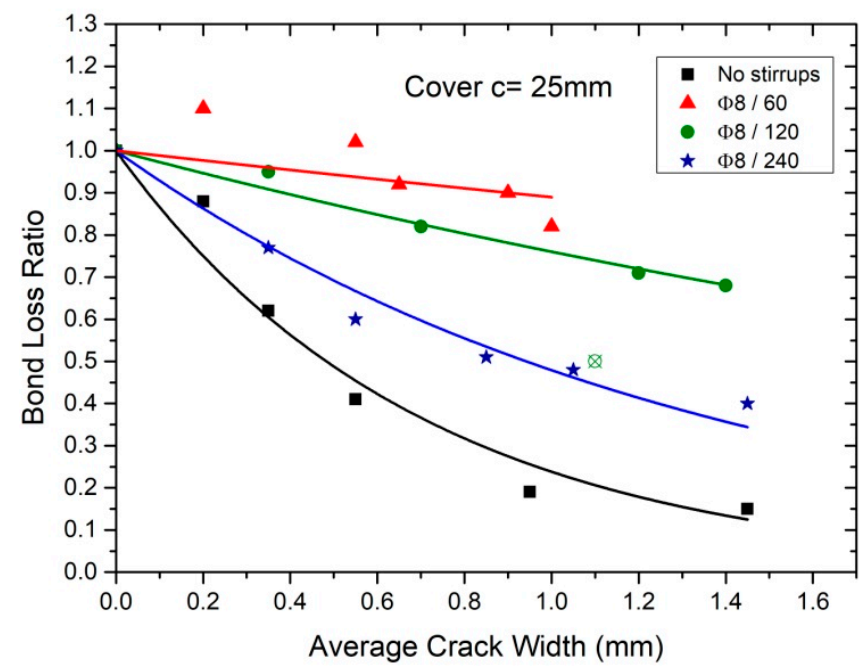

Figure 9. Exponential predictive models of bond loss in function with average crack width [21]. 
Table 2. Parameters (by regression analysis) for the exponential predictive model of bond strength loss.

\begin{tabular}{ccccc}
\hline & No Stirrups & $\mathbf{\Phi 8 / 2 4 0}$ & $\mathbf{\Phi 8 / 1 2 0}$ & $\mathbf{\Phi 8 / 6 0}$ \\
\hline $\boldsymbol{A}$ & 1.435 & 0.736 & 0.274 & 0.117 \\
\hline $\mathbf{R}^{\mathbf{2}} \mathbf{( \% )}$ & 96.2 & 96.5 & 97.7 & 45.9 \\
\hline
\end{tabular}

These models indicated the significant effect of the presence and density of stirrups on the degradation rate of bond loss in RC elements. In particular, the densification of stirrups in RC specimens benefit bond behavior by delaying the reduction in bond strength due to steel corrosion. In the case of specimens without stirrups, the bearing capacity dramatically decreases at a percentage of $85 \%$ (for mass loss equal to $7.73 \%$ ), whereas specimens with dense stirrups ( $\Phi 8 / 60 \mathrm{~mm}$ ) show a slight drop of $18 \%$ (for mass loss equal to $8.68 \%$ ), respectively. Hence, the presence of dense stirrups spacing has a significantly positive influence on the low degradation rate of the initial (uncorroded) bearing capacity of RC specimens.

As shown in Figure 10, extending this investigation and focusing on the values of maximum pull-out force and, subsequently, on bond strength, and not bond loss, the role of stirrups spacing is more highlighted, as bonding between steel and concrete degrades due to corrosion and the developed maximum pull-out force drops. The usage of dense transverse reinforcement contributes to bond behavior, not only reducing the bond loss rate, but leading to greater values of maximum pull-out force due to confinement.

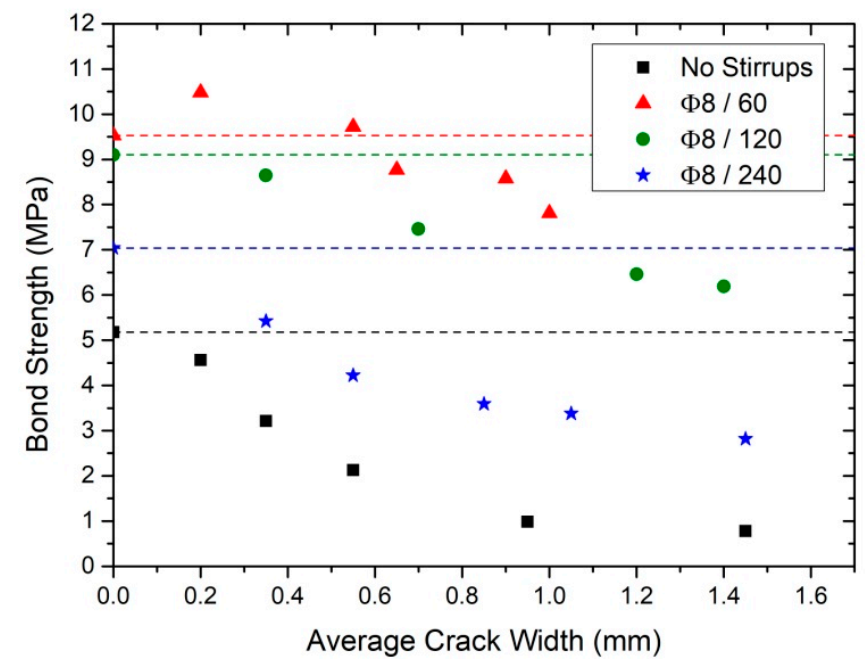

Figure 10. Bond strength values in function with average crack width.

In an effort to estimate the influence of stirrups spacing on non-corroded condition, the presence of wide stirrups $(\Phi 8 / 240 \mathrm{~mm})$ presents a maximum bond strength equal to $7.04 \mathrm{MPa}$, whereas quite dense $(\Phi 8 / 120 \mathrm{~mm})$ and dense stirrups $(\Phi 8 / 60 \mathrm{~mm})$ are equal to 9.10 and $9.53 \mathrm{MPa}$, respectively. The percentages attributing the increase in bond strength against specimens without stirrups are $35.9 \%$, $75.6 \%$ and $84 \%$, respectively. It is noteworthy that quite dense stirrups spacing $(\Phi 8 / 120 \mathrm{~mm})$ results in sufficient bond strength levels, whereas further densification leads to a minor increase in bond strength, which nevertheless delays the bond loss. Extrapolating the abovementioned on real RC structures, stirrups' densification above a certain threshold, is considered inappropriate since it could lead, on the one hand, to a substantial increase in costs and on the other hand to a rapid rise in corrosion rate, due to the potential increase.

Moreover, bond stress-relative slip curves are exported from pull-out tests for each corrosion level and for each category of stirrups spacing, respectively. The typical curves of uncorroded and corroded specimens are shown in Figure 11. 


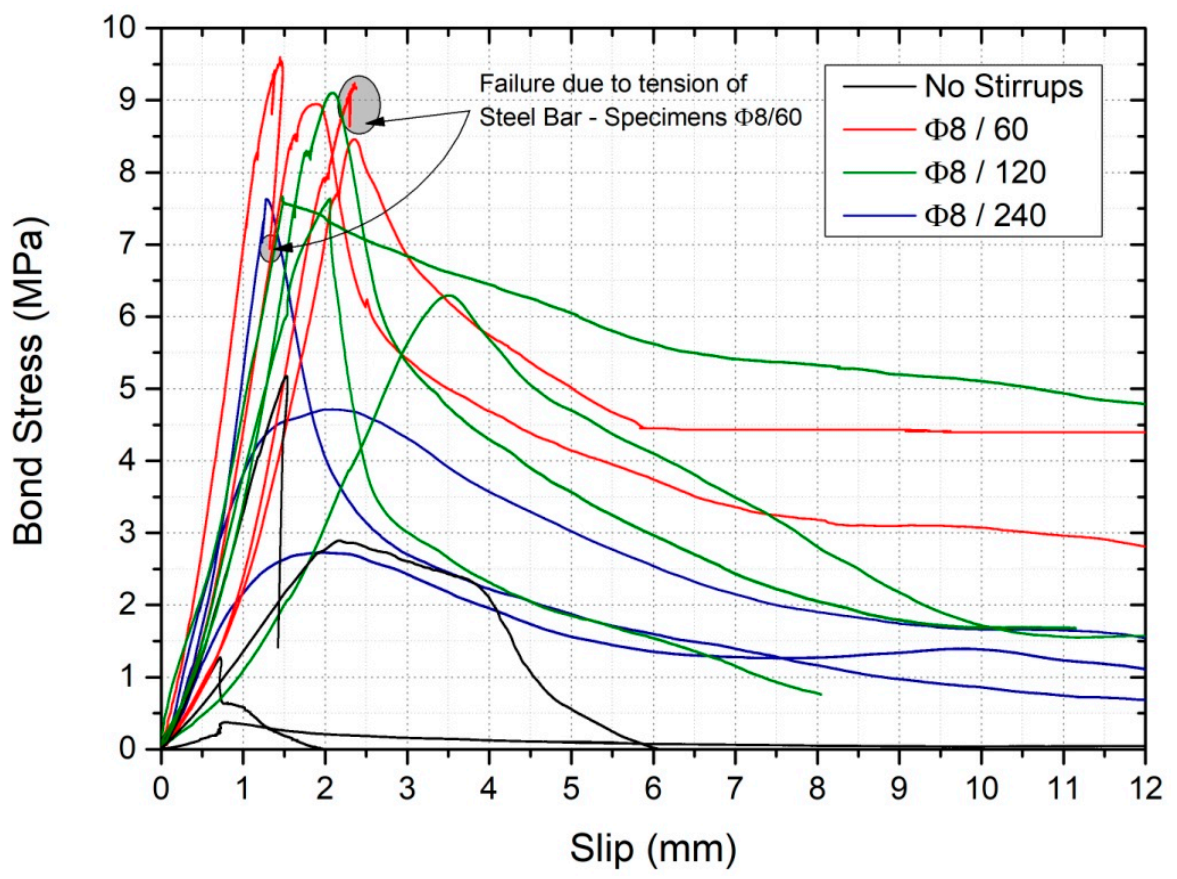

Figure 11. Bond stress-slip curves obtained from pull-out tests.

The harmful influence of the corrosion phenomenon on the bond behavior between steel and concrete can be seen examining the bond stress-slip curves of Figure 11 and in a particular group of specimens without stirrups. Uncorroded specimens-where no surface cracking had been initially observed-showed a quasi-linear relationship between bond stresses and relative slip until the point of bond strength's development. During this phase, cracks occurred parallel to the axis of steel bar, and gradually were developed due to the radial stresses, which were transferred from steel to concrete. After the development of bond strength, a sharp decline in bond stresses and complete bond loss followed. In the case of corroded specimens (without stirrups), intense surface concrete cracking was recorded, due to steel corrosion, even in low mass loss levels. As a result of this cracking, bond behavior degraded dramatically, as confirmed by the corresponding curves of Figure 11, since the steel-concrete interface is damaged by the corrosion oxides and the confinement level is deteriorated by the cracks in concrete cover.

On the other hand, as shown by the groups of specimens with stirrups, surface cracking and the degree of bond loss is strongly correlated with stirrups spacing. In particular, specimens with quite wide stirrups $(\Phi 8 / 240 \mathrm{~mm})$ showed that transverse reinforcement has a positive impact on bond behavior in uncorroded conditions, as greater values of bond stress were indicated. However, when corrosion occurs, accompanied by surface concrete cracking, bond resistance degrades, as was reflected in responding curves, where bond strength is reduced significantly, and subsequently low values of residual bond stress were recorded.

A greater contribution of stirrups to bond behavior was noticed on specimens with quite dense stirrups spacing $(\Phi 8 / 120 \mathrm{~mm})$, where even higher bond strength values are indicated, and while bond behavior degrades due to corrosion damage, does not demonstrate a massive drop, mainly due to confinement. In addition, in the case of dense stirrups $(\Phi 8 / 60 \mathrm{~mm})$, the full use of bond behavior, even after corrosion damage, occurs, with residual bond stress recorded after the peak in bond strength. It is also noteworthy that specimens of this category finally ended due to failure under tension. Thus, densification of stirrups makes full use of the bearing capacity of steel reinforcing bars and, subsequently, of RC elements. From the aforementioned, it becomes obvious that the use of dense stirrups $(\Phi 8 / 60 \mathrm{~mm})$ leads to full bonding between steel and concrete, in uncorroded and corroded conditions, respectively, marking both high bond strength and high residual bond stress after the ultimate pull-out force. 
To conclude, it should be noticed that in all groups of specimens with stirrups, the relative slip at bond strength is between 1 and $3 \mathrm{~mm}$, regardless of corrosion damage or concrete cracking. This is explained by the ribs geometry of steel bars, since it is commonly accepted that slip is mostly due to the crushing of concrete in front of the ribs. As mentioned before, the corrosion of steel reinforcing bars is accompanied with intense pits on the surface, causing a reduction in the total loss of ribs. It is also noteworthy that corrosion damage on the steel surface is mainly depicted only on the outer half of the steel bar's circumference, adjacent to the free surface of specimens, as Figure 12 shows.

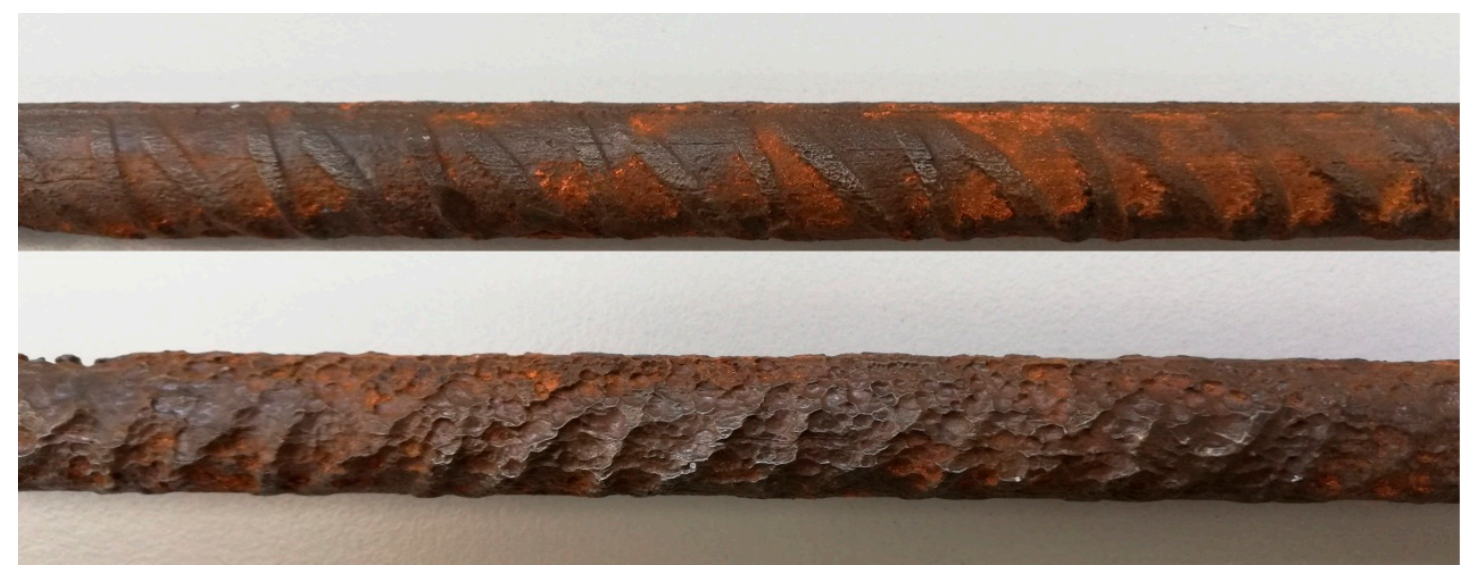

Figure 12. (Up) Inner half of steel bar's circumference. (Down) Outer half of steel bar's circumference.

\section{Conclusions}

In the current manuscript, an extensive experimental study was conducted on RC elements, where the influence of steel bar's corrosion damage and stirrups spacing on bond behavior between steel and concrete was investigated, in function with the average width of surface concrete cracking. From the present experimental study, the following outcomes were obtained:

1. Corrosion of the main steel bar causes surface concrete cracking, the width of which is closely related to the existence and densification of stirrups. The increased density of stirrups, on the one hand, contributes to the reduction in the range of surface cracking and on the other hand, to the reduction in the bond loss rate in corrosion conditions;

2. In non-corroded conditions, the use of wide stirrups $(\Phi 8 / 240 \mathrm{~mm})$ enhances the bond strength, in uncorroded conditions, by about $36 \%$ in comparison with a group of specimens without stirrups. However, in corrosion conditions, an $8.5 \%$ mass loss of reinforcing bar leads to about a $60 \%$ reduction in bond strength compared to those of uncorroded specimens;

3. Specimens with quite dense stirrups $(\Phi 8 / 120 \mathrm{~mm})$ indicated higher bond strength values in non-corroded specimens, and bond strength degrades by about $32 \%$ due to an $8.5 \%$ mass loss of the reinforcing bar;

4. Dense stirrups spacing, specimens with $\Phi 8 / 60 \mathrm{~mm}$, ensure a high level of bond behavior, either in terms of bond strength or of residual bond stress, both in uncorroded and corroded conditions.

Author Contributions: K.K. performed the preparation of RC specimens and the experimental procedure. K.K. and C.A. contributed to the methodology and technical interpretation of the results. K.K. and C.A. discussed the results and wrote the manuscript. C.A. supervised the project. All correspondence should be addressed to K.K. All authors have read and agreed to the published version of the manuscript.

Funding: This research received no external funding.

Conflicts of Interest: The authors declare no conflict of interest. 


\section{References}

1. Koch, G.; Varney, J.; Thompson, N.; Moghiss, O.; Gould, M.; Payer, J. International Measures of Prevention, Application, and Economics of Corrosion Technologies Study; Jacobson, G., Ed.; NACE International: Houston, TX, USA, 2016.

2. Hou, B.; Li, X.; Ma, X.; Du, C.; Zhang, D.; Zheng, M.; Xu, W.; Lu, D.; Ma, F. The cost of corrosion in China. NPJ Mater. Degrad. 2017, 1,1-10. [CrossRef]

3. Angst, U.M.; Geiker, M.R.; Michel, A.; Gehlen, C.; Wong, H.; Isgor, O.B.; Elsener, B.; Hansson, C.M.; François, R.; Hornbostel, K.; et al. The steel-concrete interface. Mater. Struct. 2017, 50, 143. [CrossRef]

4. Hime, W.G.; Backus, L.A.; Li, C.Q. Modeling Time-to-Corrosion Cracking in Chloride Contaminated Reinforced Concrete Structures. Discussions and Closure. ACI Mater. J. 1999, 96, 675-681.

5. Apostolopoulos, C.; Papadakis, V. Consequences of steel corrosion on the ductility properties of reinforcement bar. Constr. Build. Mater. 2008, 22, 2316-2324. [CrossRef]

6. Elbusaefi, A.A. The Effect of Steel Bar Corrosion on the Bond. Strength of Concrete Manufactured with Cement Replacement Materials; Cardiff University: Wales, UK, 2014.

7. Fu, X.; Chung, D. Effect of corrosion on the bond between concrete and steel rebar. Cem. Concr. Res. 1997, 27, 1811-1815. [CrossRef]

8. Torres-Acosta, A.A.; Navarro-Gutierrez, S.; Terán-Guillén, J. Residual flexure capacity of corroded reinforced concrete beams. Eng. Struct. 2007, 29, 1145-1152. [CrossRef]

9. Rodriguez, J.; Ortega, L.M.; Garda, A.M. Assessment of Structural Elements with Corroded Reinforcement. In Proceedings of the International Conference Corrosion and Corrosion Protection of Steel in Concrete, Sheffield, UK, 24-28 July 1994; pp. 172-185.

10. Rodriguez, J.; Ortega, L.M.; Casal, J.; Diez, J.M. Corrosion of reinforcement and service life of concrete structure. In Proceedings of the 7th International Conference on Durability of Building Materials and Components, London, UK, 19-23 May 1996; pp. 117-126.

11. Torres-Acosta, A.A.; Martnez-Madrid, M. Residual Life of Corroding Reinforced Concrete Structures in Marine Environment. J. Mater. Civ. Eng. 2003, 15, 344-353. [CrossRef]

12. Vidal, T.; Castel, A.; François, R. Analyzing crack width to predict corrosion in reinforced concrete. Cem. Concr. Res. 2004, 34, 165-174. [CrossRef]

13. Zhang, R.; Castel, A.; François, R. Concrete cover cracking with reinforcement corrosion of RC beam during chloride-induced corrosion process. Cem. Concr. Res. 2010, 40, 415-425. [CrossRef]

14. Zhao, Y.; Yu, J.; Hu, B.; Jin, W. Crack shape and oxide distribution in corrosion-induced cracking concrete. Corros. Sci. 2012, 55, 385-393. [CrossRef]

15. Bossio, A.; Montuori, M.; Bellucci, F.; Lignola, G.; Prota, A.; Cosenza, E.; Manfredi, G. Structural modeling and monitoring of corrosion. In Proceedings of the 1st International Conference on Concrete Sustainability, Tokyo, Japan, 27-29 May 2013; pp. 551-558.

16. Andrade, C.; Cesetti, A.; Mancini, G.; Tondolo, F. Estimating corrosion attack in reinforced concrete by means of crack opening. Struct. Concr. 2016, 17, 533-540. [CrossRef]

17. Bossio, A.; Lignola, G.P.; Fabbrocino, F.; Monetta, T.; Prota, A.; Bellucci, F.; Manfredi, G. Nondestructive assessment of corrosion of reinforcing bars through surface concrete cracks. Struct. Concr. 2017, 18, $104-117$. [CrossRef]

18. ACI 408R-03. Bond. and Development of Straight Reinforcing Bars in Tension; ACI: Farmington Hills, MI, USA, 2012.

19. Abosrra, L.; Ashour, A.F.; Youseffi, M. Corrosion of steel reinforcement in concrete of different compressive strengths. Constr. Build. Mater. 2011, 25, 3915-3925. [CrossRef]

20. Zandi, K.; Coronelli, D. Anchorage Capacity of Corroded Reinforcement: Eccentric Pull-Out Tests on Beam-End Specimens; Report No. 2010-06; Department of Civil and Environmental Engineering, Chalmers University of Technology: Goteborg, Sweden, 2010.

21. Apostolopoulos, C.A.; Koulouris, K.F.; Apostolopoulos, A.C. Correlation of Surface Cracks of Concrete due to Corrosion and Bond Strength (between Steel Bar and Concrete). Adv. Civ. Eng. 2019, 2019, 1-12. [CrossRef]

22. Fischer, C.; Ozbolt, J. An Appropriate Indicator for Bond Strength Degradation due to Reinforcement Corrosion. In Proceedings of the 8th International Conference on Fracture Mechanics of Concrete and Concrete Structures (FraMCoS), Toledo, Spain, 11-14 March 2013; pp. 1828-1835. 
23. Yalciner, H.; Eren, O.; Sensoy, S. An experimental study on the bond strength between reinforcement bars and concrete as a function of concrete cover, strength and corrosion level. Cem. Concr. Res. 2012, 42, 643-655. [CrossRef]

24. Hanjari, K.Z.; Lundgren, K.; Coronelli, D. Bond capacity of severely corroded bars with corroded stirrups. Mag. Concr. Res. 2011, 63, 953-968. [CrossRef]

25. Lin, H.; Zhao, Y.; Ožbolt, J.; Reinhardt, H.-W. Bond strength evaluation of corroded steel bars via the surface crack width induced by reinforcement corrosion. Eng. Struct. 2017, 152, 506-522. [CrossRef]

26. BS EN. 206-1 Concrete-Part 1: Specification, Performance, Production and Conformity; British Standards Institution: London, UK, 2000.

27. Jia, J.X.; Song, G.; Atrens, A. Boundary element method predictions of the influence of the electrolyte on the galvanic corrosion of AZ91D coupled to steel. Mater. Corros. 2005, 56, 259-270. [CrossRef]

28. Jia, J.X.; Atrens, A.; Song, G.; Muster, T.H. Simulation of galvanic corrosion of magnesium coupled to a steel fastener in $\mathrm{NaCl}$ solution. Mater. Corros. 2005, 56, 468-474. [CrossRef]

29. G01 Committee. Practice for Operating Salt Spray (Fog) Apparatus; ASTM International: West Conshohocken, PA, USA, 2019.

30. Valdez-Salas, B.; Ramirez, J.; Eliezer, A.; Schorr, M.; Ramos, R.; Salinas, R. Corrosion assessment of infrastructure assets in coastal seas. J. Mar. Eng. Technol. 2016, 15, 124-134. [CrossRef]

31. Apostolopoulos, C.; Drakakaki, A.; Basdeki, M. Seismic assessment of a reinforced concrete column under seismic loads. Int. J. Struct. Integr. 2018, 10, 41-54. [CrossRef]

32. Lin, H.; Zhao, Y.; Yang, J.-Q.; Feng, P.; Ozbolt, J.; Ye, H. Effects of the corrosion of main bar and stirrups on the bond behavior of reinforcing steel bar. Constr. Build. Mater. 2019, 225, 13-28. [CrossRef]

33. ASTM C234-91a. Standard Test. Method for Comparing Concretes on the Basis of the Bond Developed with Reinforcing Steel (Withdrawn 2000); ASTM International: West Conshohocken, PA, USA, 1991.

34. Mak, M.W.T.; Desnerck, P.; Lees, J.M. Corrosion-induced cracking and bond strength in reinforced concrete. Constr. Build. Mater. 2019, 208, 228-241. [CrossRef]

35. Holly, I.; Bilčík, J. Modelling of Reinforcement Corrosion in Concrete. In Proceedings of the 22nd International Conference Engineering Mechanics, Svratka, Czech Republic, 9-12 May 2016.

36. Holly, I.; Bilčík, J. Effect of reinforcement corrosion on bond behavior. Procedia Eng. 2013, 65, $248-253$.

37. Koteš, P.; Vi`can, J. Influence of Reinforcement Corrosion on Moment and Shear Resistance in Time of RC Bridge Girder. In Proceedings of the Eighth International Conference on Bridge Maintenance, Safety and Management (IABMAS 2016), Foz do Iguaçu, Brazil, 26-30 June 2016; pp. 1923-1928.

38. Brodňan, M.; Koteš, P.; Vanerek, J.; Drochytka, R. Corrosion determination of reinforcement using the electrical resistance method. Mater. Technol. 2017, 51, 85-93. [CrossRef]

(C) 2020 by the authors. Licensee MDPI, Basel, Switzerland. This article is an open access article distributed under the terms and conditions of the Creative Commons Attribution (CC BY) license (http://creativecommons.org/licenses/by/4.0/). 